Bangladesh J. Bot. 49(3): 515-520, 2020 (September)

\title{
HETEROSIS FOR YIELD AND PHYSIO-BIOCHEMICAL TRAITS IN BREAD WHEAT (TRITICUM AESTIVUM L.) UNDER DIFFERENT ENVIRONMENTAL CONDITIONS
}

\author{
ViJay Sharma ${ }^{1 *}$ and KamaludDin ${ }^{1}$ \\ Maharana Pratap University of Agriculture and Technology, Udaipur-313001, India
}

Keywords: Heterosis, Physiological traits, Grain yield, Diallel, Bread wheat

\begin{abstract}
The heterosis study for grain yield and yield attributes was carried out in bread wheat (Triticum aestivum L.) through half diallel mating design in four environments. The pooled analysis of variance revealed significant differences between the environments for all the characters, indicating that environments had significant effect on the expression of different characters. The variance due to parents and $F_{1}$ was also significant for all the characters, indicating significant difference between parents and hybrids and average heterosis was there. The magnitude of heterobeltiosis and standard heterosis altered for all the crosses and for all the characters. For the traits viz., total protein content, chlorophyll content, proline content, chlorophyll stability index and grain yield per plant quite a large number of crosses manifested positive significant heterosis over the checks. The hybrids HI $1544 \times$ HD 2987, Raj $4037 \times$ HD 2987, PBW $175 \times$ HD 2987, HD $2932 \times$ Raj 4079 and PBW $175 \times$ Lok 1 exhibited the highest, significant and positive heterotic effect and mean performance for grain yield per plant and some of its important component traits. This could be exploited commercially for heterosis breeding in wheat.
\end{abstract}

\section{Introduction}

Triticum aestivum L. is an annual autogamous crop with chromosome number $2 \mathrm{n}=6 \mathrm{x}=42$. Wheat is the staple food for over 35 per cent of world population (IDRC 2003). It is popularly known as 'Stuff of life or King of the cereals' because of the acreage occupied, high productivity and the prominent position it holds in the international food grain trade.

Globally Triticum aestivum wheat is most important species as it covers 90 per cent of the area and durum wheat which covers about 9 per cent of the total area while Triticum dicoccum and Triticum monococcum wheat cover less than the one per cent of the total area (Sharma et al. 1995). The main wheat growing countries include China, India, USA, Russia, France, Canada, Turkey, Australia and Ukrain. In India, area and production of wheat during year 2014 - 15 was recorded 30.97 million ha and 88.94 million tonnes with an average productivity of $2872 \mathrm{~kg} / \mathrm{ha}$ (DAC\&FW, 2015). Nutritionally, wheat grain contains $60-68 \%$ starch, $6-21 \%$ protein, 2.0 $2.5 \%$ cellulose, $1.5-2.0 \%$ fat, $1.8 \%$ minerals and vitamins (Koehler and Wieser 2013). Nearly, 80 per cent of wheat protein contains gluten which in turn comprises of glutenin and gliadin. Glutenin provides extensibility whereas gliadin provides viscosity to dough.

In autogamous crop like wheat, utility of heterosis depends primarily upon the degree and direction of heterosis. Wheat breeders dealing with various aspects of hybrid wheat found that the economic heterosis for grain yield, on a large plot basis, ranged from 6 (Borghi et al. 1986) to as high as 41 percentages (Yadav and Murty 1976). The study was conducted for identifying the best cross combination(s) that could be used for production of hybrid wheat at commercial level as well as isolation of pure lines among the progenies of heterotic $F_{1}$ s for further amelioration of grain yield in wheat.

*Author for correspondence: <107vijaysharma@gmail.com>. 'Department of Genetics and Plant Breeding, Banda University of Agriculture and Technology, Banda- 210001, India. 


\section{Materials and Methods}

Eight diverse genotypes (Table 1) selected on the basis of broad range of genetic diversity for yield and physio-biochemical traits, geographical origin, heat tolerance and their suitability for different yield traits were crossed in half diallel fashion resulting in $28 \mathrm{~F}_{1} \mathrm{~s}$ at Research Farm, Rajasthan College of Agriculture, Udaipur during the year 2014 - 15. These 8 parents and their 28 $F_{1}$ s and 2 checks viz., HI 1563 and HD 2967 were grown in a randomized block design with three replications under early $\left(\mathrm{E}_{1}\right)$, normal $\left(\mathrm{E}_{2}\right)$, late $\left(\mathrm{E}_{3}\right)$ and very late $\left(\mathrm{E}_{4}\right)$ sown conditions. The environments were created by four different date of sowings viz., early sown (October 27, 2015), normal sown (November 17, 2015), late sown (December 07, 2015) and very late sown (December 27, 2015). Row-to-row and plant-to-plant distances were $30 \mathrm{~cm}$ and $10 \mathrm{~cm}$, respectively in each environment. Recommended plant protection procedures were followed for raising the crop in all the environments.

Table 1. List of parent material of wheat used in the experiment.

\begin{tabular}{cll}
\hline S.N. & Name of cultivar & Pedigree \\
\hline 1. & HD 2932 (PUSA WHEAT 111) & KAUZ/STAR//HD 2643 \\
2. & GW 366 & DL 802-3/GW 232 \\
3. & Raj 4037 & DL 788-2/RAJ 3717 \\
4. & PBW 175 & HD 2160/WG 1025 \\
5. & HI 1544 (PURNA) & HINDI 62/BOBWHITE/ CPAN 2099 \\
6. & Raj 4079 & UP 2363/WH 595 \\
7. & HD 2987 (PUSA BAHAR) & HI1011/HD2348//MENDOS//IWP72/DL 153-2 \\
8. & LOK 1 & S-308/S 331, \\
\hline
\end{tabular}

The observation was recorded on five randomly selected competitive plants from each plot in each replication in case of parents, $F_{1} s$ and checks in all the four environments separately on seven distinct characters. The data on grain yield per plant, leaf canopy temperature, proline content, chlorophyll content, chlorophyll stability index, heat injury and total protein content in grain were recorded for statistical analysis. The mean value of the recorded observation was subjected to ANOVA using the standard procedures of Panse and Sukhatme (1985). Heterosis, heterobeltiosis and economic heterosis were calculated according to the method suggested by Shull (1909), Fonseca and Patterson (1968) and Meredith and Bridge (1972), respectively. To calculate heterobeltiosis and economic heterosis parent with higher mean values was considered desirable for all the characters except leaf canopy temperature, heat injury and total protein content in grain where lower mean values were considered desirable. The economic heterosis was calculated over the check for a particular character.

\section{Results and Discussion}

The pooled analysis of variance over four environments (Table 2) revealed significant differences between the environments for all the traits, indicating that environments had significant effect on the expression of different characters. Similar findings were previously reported by Sharma et al. (2019). The mean squares due to parents and $\mathrm{F}_{1}$ were also significant for all the characters, indicating that between parents and between hybrids difference was significant and average heterosis was there. Parents vs. hybrids comparison were significant for grain yield per plant, proline content, chlorophyll content, chlorophyll stability index and total protein content in grain, indicating presence of overall heterosis for all these characters. Highly 
significant differences due to genotypes $\times$ environments was observed for all the characters except leaf canopy temperature and total protein content in grain which indicated influence of different environments on the expression of genotypes.

Magnitude of heterosis provides information on the extent of genetic diversity in parents of a cross and helps in choosing the parents for superior $\mathrm{F}_{\mathrm{l}} \mathrm{s}$, so as to exploit hybrid vigour. In selfpollinated crop like wheat, where commercial hybrid seed production is not feasible due to lack of suitable mechanism to produce hybrid seed, exploitation of hybrid vigour is limited. Therefore, at present heterosis per se may not be of economic value in this crop. However, it indicates genetic potential of parental combination and if the heterosis is due to epistatic gene effects, particularly of additive $\times$ additive type or due to repulsion phase linked loci, exhibiting partial or complete dominance, it is possible to fix the alleles at interacting state to preserve the heterotic effects in the pure lines (Arunachalam et al. 1984) means transgressive segregants are possible. Preservation of hybrid vigour in wheat for number of generations can favour allopolyploid nature of wheat. In addition, heterotic crosses can also generate desirable transgressive segregants in their advance generation (Arunachalam et al. 1984).

The exploitation of heterosis in crop plants is one of the major breakthroughs in plant breeding. The degree of heterosis over mid parental value has comparatively restricted scope and is of more hypothetical interest than of real-world utility. Hence, the heterosis measured in terms of superiority over the better parent and over the standard check is more treasured, which decides whether an experimental hybrid is worth exploiting or not.

The magnitude of heterosis and number of cross combinations showing heterosis over better parent and standard hybrid for grain yield per plant and its related characters are presented in Table 3. Grain yield is the trait of economic importance in wheat for which 7 hybrids over better parent and 6 hybrids over standard check variety exhibited significant and positive heterosis. Out of 28 hybrids, some exhibited significant and desirable direction of heterobeltiosis, economic heterosis for various traits such as leaf canopy temperature ( 3 and 6); proline content ( 8 and 11); chlorophyll content (5 and 13); chlorophyll stability index (12 and 8); heat injury (17 and 9) and total protein content (7 and 14), respectively.

The hybrid, Raj $4037 \times$ HD 2987 for grain yield per plant, HI $1544 \times$ Lok1 for leaf canopy temperature, HD $2932 \times$ HD 2987 for proline content, HD $2932 \times$ HD 2987 for chlorophyll content, PBW $175 \times$ HI 1544 for chlorophyll stability index, HD $2932 \times$ Raj 4079 for heat injury and Raj $4037 \times$ Lok 1 for total protein content in grain showed significant and maximum heterosis over better parent.

Maximum heterosis over standard check was observed in HI $1544 \times \mathrm{HD} 2987$ for grain yield per plant, GW $366 \times$ PBW 175 for leaf canopy temperature, HD $2932 \times$ Raj 4037 for proline content, HD $2932 \times$ HD 2987 for chlorophyll content, HD $2932 \times$ Lok 1 for chlorophyll stability index, HD $2932 \times$ Lok 1 for heat injury and HD $2932 \times$ PBW175 for total protein content in grain.

The approach of heterosis breeding is useful in development and identification of the most heterotic and useful cross combinations in order to make commercial cultivation of hybrid. For this a comparison of the first seven high yielding hybrids was made with per se performance for grain yield, heterotic effects for grain yield and heterotic effects for other related traits (Table 4). The high yielding hybrids were in general the most heterotic crosses which indicated close association between hybrid mean performance and manifestation of heterosis. The relative ranking of hybrids based on the mean performance suggested that selection of hybrids should be based on per se performance. Similar results were also reported by Rasul et al. (2002), Punia et al. (2011), Lal et al. (2003) and Kumar et al. (2014). 

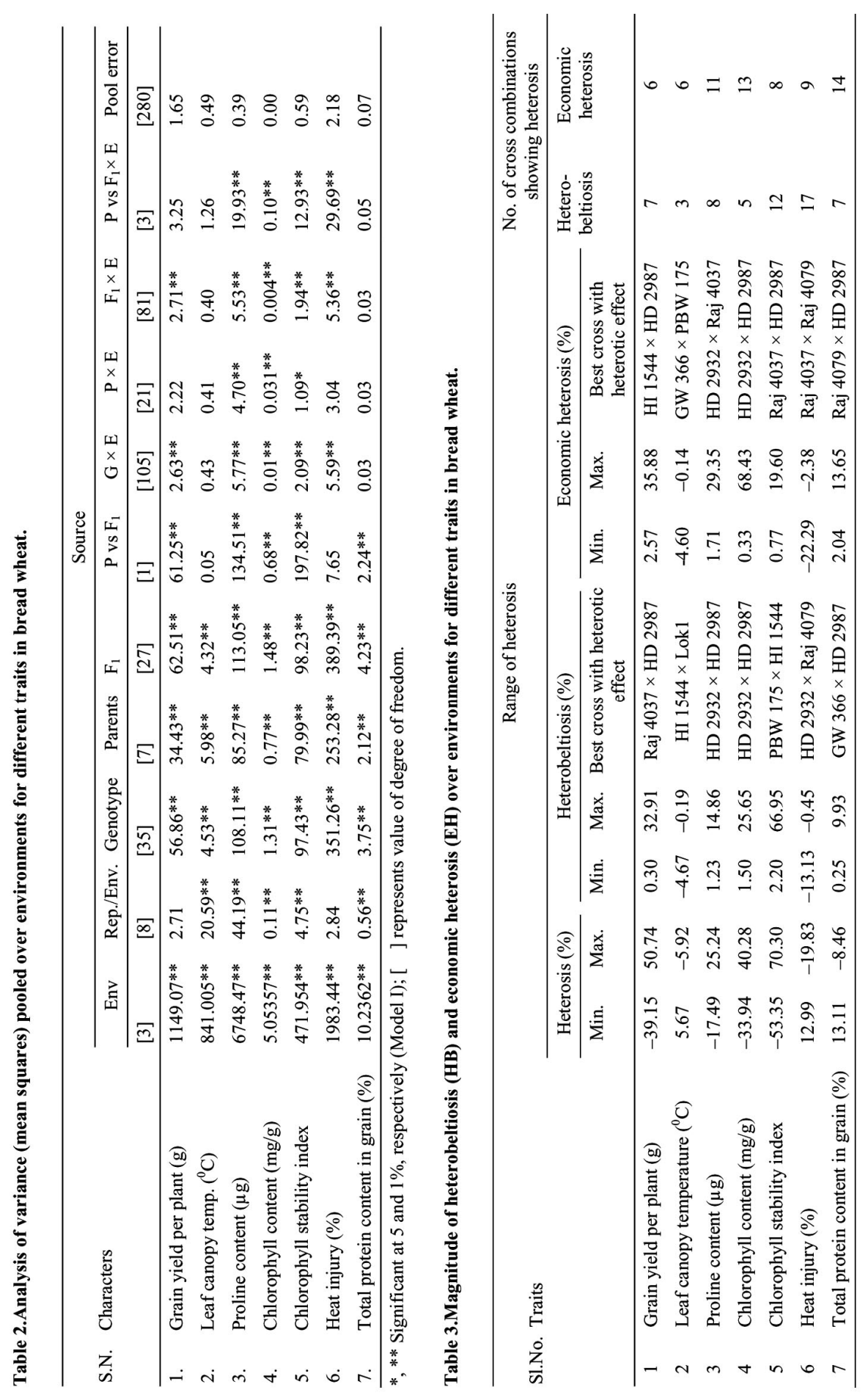
A comparative study of seven hybrids for grain yield identified on basis of per se performance (Table 4) indicated that none of the cross combinations or hybrid indicated desired heterobeltiosis and economic heterosis for all the characters studied.

Table 4. Promising hybrids identified on the basis of per se performance and economic heterosis over environments for grain yield per plant.

\begin{tabular}{ccccl}
\hline S.N. & Hybrids & $\begin{array}{c}\text { Per se performance } \\
\text { of grain yield } \\
\text { per plant }(\mathrm{g})\end{array}$ & $\begin{array}{c}\text { Economic } \\
\text { heterosis } \\
(\%)\end{array}$ & $\begin{array}{l}\text { Significant economic heterosis } \\
\text { for other traits in desired } \\
\text { direction }\end{array}$ \\
\hline 1. & HI 1544 $\times$ HD 2987 & 18.57 & $35.88^{* *}$ & GY, CSI, TP \\
2. & Raj 4037 $\times$ HD 2987 & 17.69 & $29.48^{* *}$ & GY, LCT, PC, CC, H, CSI \\
3. & PBW 175 $\times$ HD 2987 & 16.74 & $22.48^{* *}$ & GY \\
4. & HD 2932 $\times$ Raj 4079 & 16.37 & $19.79^{* *}$ & GY, LCT, PC, CC, CSI, H \\
5. & PBW 175 $\times$ Lok 1 & 15.69 & $14.78^{* *}$ & GY \\
6. & HI 1544 $\times$ Raj 4079 & 15.63 & $14.36^{* *}$ & GY, CC \\
7. & HI 1544 $\times$ Lok 1 & 15.16 & $10.96^{* *}$ & GY, CC, TP \\
\hline
\end{tabular}

** Highly significant at $1 \%$ level of significance. LCT: Leaf canopy temperature, PC: Proline content, CC: Chlorophyll content, CSI: Chlorophyll stability index, H: Heat injury, TP: Total protein content in grain and GY: Grain yield per plant.

The cross-combination HI $1544 \times$ HD 2987 exhibited significant and desired heterosis over standard checks for grain yield per plant also showed significant and desirable economic heterosis for chlorophyll stability index and total protein content in grain. The hybrids Raj $4037 \times$ HD 2987 and HD $2932 \times$ Raj 4079 expressed desirable economic heterosis grain yield, leaf canopy temperature, proline content, chlorophyll content, chlorophyll stability index and heat injury. PBW $175 \times$ HD 2987 showed desirable positive economic heterosis for grain yield per plant. These superior hybrids of wheat may be exploited at commercial level to get advantages of heterosis for grain yield and its related traits.

It is not essential that high heterosis for all the yield components just will bring about high heterosis for yield but increase in any one or two yield components traits may likewise come about into high level of heterosis for yield. The findings of present investigation clearly demonstrated that considerable heterosis did occur for all the characters studied. Thus, clearly increase in yield of $F_{1}$ hybrids is the consequence of increase in values of other yield contributing characters.

\section{Acknowledgements}

The authors express their distinctive thanks to Department of Science and Technology, Government of India, New Delhi for providing Inspire Fellowship for full-time doctoral (Ph.D.) degree programme at Maharana Pratap University of Agriculture and Technology, Udaipur, India.

\section{References}

Arunachalam V, Bandhyopadhyay A, Nigam SN and Gibbons RW 1984. Heterosis in relation to genetic divergence and combining ability in ground nut (Arachis hypogaea L). Euphytica 33: 33-99.

Borghi B, Corbellini M, Cattaneo MM, Fornasari E and Zucchelli L 1986. Modification of the sink/source relationships in bread wheat and its influence on grain yield and grain protein. Agron. J. 157: 245-254. 
DAC\&FW 2015. Directorate of Economics and Statics, Department of Agriculture Cooperation and Farmers Welfare.

Fonsecca S and Patterson FL 1968. Hybrid vigour in seven-parent diallel cross in common wheat (T. aestivum L.). Crop Sci. 2: 85-88.

IDRC 2003. International Development Research Centre, Facts and Figure on Food and Biodiversity, pp. 2 of the executive summary, available at http://www.idrc.ca/en/ev-31631-201-1-DO_Topic.html. Unless otherwise specified, this whole introduction drawn from this report.

Koehler P and Wieser H 2013. Chemistry of cereal grains. In: M. Gobbetti and Ganzle (Eds.), Chp. 2 in Handbook on Sourdough Biotechnology (pp. 11-45). New York, NY: Springer.

Kumar A, Kumar V, Kerkhi SA, Kumar S, Chand P, Kumar N, Kumar D and Kumar M 2014. Evaluation of heterosis for yield and yield related traits in bread wheat (Triticum aestivum L.). Prog. Agri. 14: 151159.

Lal C, Kumar V and Maloo SR 2013. Heterosis and inbreeding depression for some quantitative and heat tolerance characters in bread wheat (Triticum aestivum L.). J. Wheat Res. 5: 52-55.

Meredith WR and Bridge RR 1972. Heterosis and gene action in cotton (Gossypium hirsutam). Crop Sci. 12: 304-310.

Panse VC and Sukhatme PV 1985. Statistical Methods for Agricultural Workers. Indian Council of Agricultural Research, New Delhi.

Punia SS, Shah AM and Ranwah BR 2011. Genetic analysis for high temperature tolerance in bread wheat. African Crop Sci. J. 19: 149-163.

Rasul L, Khan AS and Zulfiqar A 2002. Estimation of heterosis for yield and some yield components in bread wheat. Int. J. Agri. Biol. 4: 214-216.

Sharma DJ, Yadav RK and Sharma RK 1995. Genetic variability and association of some yield components in winter x spring nursery of wheat. Adv. Plant Sci. 8: 95-99.

Sharma V, Dodiya NS, Dubey RB, Khandagale SG and Shekhawat N 2018. Estimation of heterosis for yield and some yield components in bread wheat. J. Pharmacognosy and Phytochem. 7: 1742-1745.

Shull GH 1909. A pureline method of com breeding. American Breeders Association Reports 5: 51-59.

Yadav SP and Murty BR 1976. Heterosis and combining ability in crosses of different height categories in bread wheat. Indian J. Gen. Pl. Breed. 36: 184-196.

(Manuscript received on 9 April, 2019; revised on 11 July, 2019) 